The report states that one of the most significant events of the year under review was the commissioning during June, and the official inauguration on November 29, of the zero energy reactor Nora and of the fuel processing pilot plant. The reactor was established as a joint IFA-IAEA undertaking and was designed and built by NOR-ATOM $A / S$. The research programme has been approved by the Nora Committee under its chairman, Dr. R. Ramanna of India. For this programme three fuel charges are available, the first a 3 per cent enriched fuel charge provided by the U.S. Atomic Energy Commission, the second a reference charge of 2.5 tons of natural uranium metal, and the third a charge of elements from the Halden second core. The research programme is concentrated on the physical aspects of spectral shift controlled reactor systems.

In the spring of 1961 the design of the Jeep II reactor was reviewed in order to simplify the design and bring down costs; to introduce a flux trap; and to consider the use of the principle of spectral shift for long-term reactivity control. The reactor will be built and started as a heavy-water reactor and will be housed in a thermally insulated steel containment shell $22.4 \mathrm{~m}$ high and $22 \mathrm{~m}$ in diameter to withstand a pressure of $0.15 \mathrm{~kg} / \mathrm{cm}^{2}$. The erection of the shell and control building was started in the summer of 1961. The reactor will be moderated and cooled by heavy water and fuelled by slightly enriched $\mathrm{UO}_{2}$ canned in aluminium tubes. Jeep $I I$ is planned to go critical during 1965 , and it is estimated that the thermal neutron flux at a power-level of $2 \mathrm{MW}$ in the centre of the reactor will be about $1.5 \times 10^{13}$ neutrons $/ \mathrm{cm}^{2}$ sec.
The experimental programme at the Halden reactor continued with the first fuel charge up to May, when the reactor was shut down prior to the insertion of the second, enriched core. During the second phase of the programme the reactor will be operated at 20 MW instead of $6 \mathrm{MW}$ at $155^{\circ} \mathrm{C}$. The programme so far includes the determination of data on various reactor physics parameters, such as temperature and water-level coefficients, and the critical buckling as a function of moderator temperature has been calculated. Modifications, partly based on experience gained during the operation of the reactor, which will be introduced for operation at the higher power, include the installation of a new steam transformer to be operated in parallel with the original one, and a tertiary loop with a new steam generator for dissipation of the steam produced.

During 1961 two new wings of the NetherlandNorwegian Reactor School were taken into use, thus increasing the capacity of the school considerably by providing facilities for experimental work in reactor engineering, physics and radiochemistry. The nine weeks standard course in fundamentals of nuclear engineering was held twice, and during March a course on analogue computer techniques and their application to nuclear engineering and chemical processing problems was held for the staff at Kjeller and Halden.

The report concludes with details of the safety work and health physics; the technical information service including a list of Kjeller Reports and Halden Project Reports issued during the year; international co-operation; and the numbers and distribution of the staff at the Institute on December 31, 1961.

\title{
PUBLICATIONS OF THE NATIONAL PHYSICAL LABORATORY, TEDDINGTON
}

\footnotetext{
GOUR new booklets in the series Notes on Applied Science of the National Physical Laboratory, Teddington, have recently been published*. The first, No. 25 in the series, entitled Hydrometers and Hydrometry, deals with basic considerations of air buoyancy, surface tension and the spacing of the scale; the general use of hydrometers with examples; the verification and adjustment of hydrometers with particular reference to practice at the National Physical Laboratory; and types of hydrometer scale and the relationship between scales. It is emphasized that ordinary hydrometers of constant mass are convenient instruments for the measurement of the density and specific gravity of liquids, and that greater accuracy can be obtained by their use than is generally realized. Though British Standard 718: 1960 contains considerable information on hydrometers and hydrometry, several interesting points outside the scope of the Standard are dealt with in the booklet.

* Department of Scientific and Industrial Research. National ${ }^{*}$ Department of Scientific and Industrial
Physical Laboratory. Notes on Applied Science.

No. 25: Hydrometers and Hydrometry. By J. B. Rands and P. H. Bigg. Pp. iv $+31+1$ plate. $28.6 d$. net.

No. 27: Inspection of Gauging Dimensions Involving Linear and Angular Measurements. By Dr. J. C. Evans and C. O. Taylerson. Pp. v+42. 3s. 6d. net.

No. 28: The Measurement of Frequency. By Dr. I. Essen, E. G. Hope and $\mathrm{K}$. Morris. Pp. $\mathrm{v}+17$. $18.9 d$. net.

No. 29: Physical Photometry. By Dr. B. H. Crawford. Pp.iv +16. 18. $9 d$. net.

(London: H.M.S.O., 1962.)
}

The information given in No. 27, Inspection of Gauging Dimensions Involving Linear and Angular Measurements, is intended to assist engineering inspectors in checking gauges, jigs and workpieces, involving combined measurements of length and angle. The use of the Universal Measuring Block manufactured by the Pitter Gauge and Tool Co. Ltd. is described, and full particulars of the measuring equipment associated with it are given together with the types of measurement which can be made with the equipment. A principal purpose of the booklet is to present a general procedure for the type of measurement in which the required dimension must be obtained by calculation from indirect measurements of the work. Examples of both the simpler direct measurement technique and of the indirect measurement procedure are given and fully explained. The derivation of the associated trigonometrical formulæ required in the calculations are set out in an appendix.

Measurements of frequency with an accuracy approaching one part in $10^{10}$ are now required not only for precision laboratory measurements but also for routine operations. The techniques which make such measurements possible are briefly discussed in No. 28 of the series, entitled The Measurement of Frequency, where an account is given also of the more usual types of frequency meter utilizing a resonant 
circuit. The standard of frequency at the National Physical Laboratory is a cæsium atomic resonator and this is used to calibrate the quartz clock working standards. These in turn monitor the carrier frequencies of a number of transmitting stations, with the call sign $M S F$, which are operated from the Laboratory from the British Post Office Station at Rugby. Details of these transmissions and of the more powerful carrier wave of the station $G B R$, which is controllod by the $M S F$ standard, are given in the booklet. Separate sections deal with frequency synthesis and measurement and with cavity-resonator frequency meters and their testing and calibration. These meters are most useful in a wide field of applications where an accuracy of about one part in $10^{4}$ is adequate.

The fourth booklet, No. 29, Physical Photometry by Dr. B. H. Crawford, describes those procedures in photoelectric photometry which have their worth in precise measurement and which are in regular use at the National Physical Laboratory. Photometry is essentially the measurement of radiant energy by a selective receiver, the human eye, but individual eyes vary and it is assumed that there is a statistically satisfactory 'standard $\Theta y \Theta$ '. A value for the photopic (light-adapted) standard observer was accepted in 1933 by the International Committee on Weights and Measures and for the scotopic (darkadapted) by the Commission International de l'Éclairage in 1951. These values are tabulated in the booklet. After a general examination of the photoreceptors in present-day use, the spectral correction of vacuum emission photocells and of radiation thermopiles and bolometers is discussed in some detail. Finally, there are two sections dealing with amplifiers and photometers.

S. WEINTROUB

\section{PETROLEUM CHEMISTRY: U.S.S.R.}

$\mathrm{T}$ HE past decade has witnessed a spectacular commercial development of the petroleum indus. try in the manufacture and marketing of petroleumderivod organic and inorganic chemicals in Great Britain. Julian M. Leonard, in a recent presidential address to the Institute of Petroleum ( $J$. Inst. Pet., $48,271,1962)$, quotes figures showing that the share of petroleum as raw material for the chemical industry has increased from about 9 per cent in 1949 to 47 per cont in 1959 , at present running at more than 50 per cent and anticipated to reach 65 per cent when 1962 figures aro available. In the United States the production of petrochemicals was a much earlier development than in the United Kingdom and it is estimated that to-day some 80 per cent of organic chemicals manufactured there are based on petroleum. It is doubtful whether the petroleum tochnologist, not directly concerned with modern refinery flowsheets, is himself aware of the phenomenal expansion in this new field and of its technical and economic significance in the future of the world's chemical industry. Certainly the layman is even less informed on this subject, probably because it is not one that can be easily propagated in the popular Press.

The starting point of petrochemicals, as Leonard stated, is the complex of naturally and artificially produced petroleum gases from which are synthesized ethylene, propylene, butadiene, benzene, toluene, xylene, etc. Some of the more important products stemming from these foundations are synthetic rubber, synthetic fibres, detergents, thermoplastics, and agricultural insecticides and fertilizers, many of these roplacing materials formerly derived from purely natural, mainly vegetable resources. The possibility of producing edible oils and fats from petroleum, although not yet matured on a large scale, is none the less practicable and in itself opens up another highly specialized prospect in the chemical industry.

In the academic and technical worlds concerned with petrochemicals there has naturally evolved an extensive literature during the course of development of this fascinating subject, especially in the United States and the United Kingdom. Western European countries have also contributed their share. In these spheres language is no bar to the past or present records of research, discovery or progress. But the same cannot be said of published work in the U.S.S.R., which despite its magnitude and value, must necessarily remain a 'closed book' to all but those chemists who can read the Russian publications per se. The increasing amount of research in the U.S.S.R. on the nature and configuration of petroleum hydrocarbons, composition of sulphur and nitrogen-bearing compounds, and on conversion processes used in the manufacture of petrochemicals, is of such a volume that it has led to the launching in the U.S.S.R. of a new periodical Neftelchimiya-Petroleum Chemistry, which aims at co-ordinating the work of "investigators on the chemistry of petroleum and on the petroloum chemicals industry". This is the quote from the foreword to the English version of Petroleum Chemis. try: U.S.S.R., a quarterly published by Pergamon Press for Pergamon Institute, Oxford, of which the first volume and number* has just appeared in the United Kingdom, under the editorship of D. L. Samuel with translator B. J. Hazzard. The former writes: "Such work is of great interest to all workers in similar or related fields and they will doubtless be well pleased with the opportunitios of reading of the work of their Russian colleagues, made possible by the issue of an English edition. The papers of greatest interest to western research workers are translated in full and an abstract provided of those of lesser appeal".

The first volume of this English publication contains translations of twenty-five original papers by Russian scientists of considerable academic and technical importance in the modern realm of petroleum chemistry in general and petrochemicals in particular. Abstracts of other relevant papers in Neftekhimiya, running to a total of thirty-eight (of which the publishers are prepared to supply full English translations), conclude what, in future numbers, is obviously destined to become a most valuable medium of international exchange of knowledge of petroleum chemistry conceived in the fullest sense of its modern terms of reference.

\section{H. B. MILNER}

- Petroleum Chemistry: U.S.S.R., 1, No. 1; 1962. Publisher guarterly. Translation editor, D. L. Samuel. Pp, 1-218. (London and (85 dollars). 